\title{
O papel da moradia estudantil na edificação da educação integral no Instituto Federal Catarinense - IFC: limites e potencialidades
}

\section{The role of student housing in the building of integral education in the Instituto Federal Catarinense - IFC: limits and potentialities}

\author{
El papel de la vivienda estudiantil en el edificio de educación integral en el \\ instituto federal Catarinense - IFC: límites y potencialidades
}

Camillo, Eliane Juraski ${ }^{1}$ (Florianópolis, SC, Brasil) Orcid: http://orcid.org/0000-0002-6385-6629

Figueredo, Daiana Colombro² (Florianópolis, SC, Brasil)

Orcid: http://orcid.org/0000-0003-1526-8889

\section{Resumo}

Este artigo é fruto da pesquisa realizada pelas autoras durante o Mestrado Profissional em Educação Profissional e Tecnológica-PROFEPT, no ano de 2020. O objetivo geral consistiu em investigar os limites e as potencialidades da Moradia Estudantil (ME) enquanto espaço de formação integral dos/as estudantes do Curso Técnico em Agropecuária Integrado ao Ensino Médio do Instituto Federal Catarinense-IFC. A pesquisa bibliográfica contemplou os objetivos de levantar o estado da arte da produção do conhecimento teórico/empírico acerca da ME, refletir sobre o EMI na perspectiva da formação integral dos/as sujeitos/as e compreender as possíveis mediações da escola e do trabalho na (re)construção das identidades juvenis. Foram realizadas também entrevistas narrativas, baseadas na metodologia da história oral, partindo de questões geradoras e via whatsapp, um questionário semiestruturado, haja vista que essa etapa da pesquisa foi impactada pela pandemia do novo Coronavírus. O objetivo foi averiguar as percepções de estudantes e egressos/as sobre o papel da ME enquanto espaço de formação integral. O pressuposto confirmado foi de que a vivência na ME contribui na formação humana integral dos/as sujeitos/as, contemplando sua formação cidadã, mas apresenta limitações, devido a necessidade de organização institucional para o planejamento e o acompanhamento das atividades desenvolvidas durante o tempo livre. A partir desse trabalho, será possível a ressignificação da ME para além de sua função no programa de assistência estudantil.

Palavras-chave: Moradia Estudantil. Educação Profissional. Formação Humana Integral. Juventudes.

\begin{abstract}
This article is the result of research conducted by the authors during the Professional Master in Professional and Technological Education, in the year 2020. The general objective was to investigate the limits and potentialities of Student Housing $(\mathrm{SH})$ as a space of integral formation of the students of the Technical Course in Agriculture Integrated to High School of the Instituto Federal Catarinense-IFC. The bibliographical research contemplated the objectives of raising the state of the art of the production of theoretical/empirical knowledge about the $\mathrm{SH}$, to reflect on the Integrated High School in the perspective of the integral formation of the subjects and to understand the possible mediations of the school and of the work in the (re)construction of the juvenile identities. Narrative interviews were also carried out, based on the methodology of oral history, starting with generating questions and via whatsapp, a semi-structured questionnaire, since this stage of the research was impacted by the pandemic of the new Coronavirus. The objective was to ascertain the perceptions of students and graduates about the role of $\mathrm{SH}$ as a space of integral formation. The assumption confirmed was that the experience at $\mathrm{SH}$ contributes to the integral human formation of the subjects, contemplating their citizen formation, but presents limitations due to the need of institutional organization for the planning and follow-up of the activities developed during free time. From this work, it will be possible to resign the $\mathrm{SH}$ beyond its function in the student assistance program.
\end{abstract}

Keywords: Student Residence. Professional Education. Integral Human Formation. Youths.

\footnotetext{
${ }_{1}^{1}$ Docente do Instituto Federal Santa Catarina (IFSC). juraskicamillo@gmail.com.

2 Docente do Instituto Federal Catarinense (IFC). daiqmclic@gmail.com.
} 


\section{Resumen}

Este artículo es el resultado de la investigación realizada por los autores durante el Máster Profesional en Educación Profesional y Tecnológica, en el año 2020. El objetivo general era investigar los límites y potencialidades de la Residencia de estudiantes (RE) como espacio de formación integral de los estudiantes del Curso Técnico en Agricultura Integrado a la Escuela Secundaria del Instituto Federal Catarinense-IFC. La investigación bibliográfica contempló los objetivos de elevar el estado del arte de la producción de conocimientos teóricos/empíricos sobre la RE, reflexionar sobre la escuela secundaria integrada en la perspectiva de la formación integral de los sujetos y comprender las posibles mediaciones de la escuela y del trabajo en la (re)construcción de las identidades juveniles. También se realizaron entrevistas narrativas, basadas en la metodología de la historia oral, comenzando por la generación de preguntas y mediante whatsapp, un cuestionario semiestructurado, ya que esta etapa de la investigación se vio afectada por la pandemia del nuevo Coronavirus. El objetivo era averiguar las percepciones de los estudiantes y graduados sobre el papel de la RE como espacio de formación integral. El supuesto confirmado fue que la experiencia en RE contribuye a la formación humana integral de los sujetos, contemplando su formación ciudadana, pero presenta limitaciones debido a la necesidad de organización institucional para la planificación y seguimiento de las actividades desarrolladas en el tiempo libre. A partir de este trabajo, será posible renunciar al RE más allá de su función en el programa de asistencia a los estudiantes.

Palavras-Clave: Residencia de estudiantes. Educación profesional. Formación Humana Integral. Juventud.

\section{Introdução}

A pesquisa que deu origem a esse artigo foi desenvolvida no âmbito do Curso de Mestrado Profissional em Educação Profissional e Tecnológica (PROFEPT), na linha de pesquisa "Organização e Memórias de Espaços Pedagógicos em Educação Profissional e Tecnológica”.

A motivação para a escolha do objeto da pesquisa se deu em função de que uma das autoras é servidora docente do Campus Abelardo Luz do Instituto Federal Catarinense (doravante IFC), tendo atuado como Coordenadora do Serviço Integrado de Suporte e Acompanhamento Educacional (SISAE), o qual é responsável, na instituição, pela moradia estudantil (doravante ME).

A escolha do curso pesquisado, o Curso Técnico Integrado em Agropecuária se deu pelas características da formação nessa área na instituição, envolvendo muitas vezes atividades extracurriculares, geralmente realizadas pelos/as moradores/as da ME. A escolha dos dois locais de pesquisa aconteceu no sentido de enriquecê-la, visto que estão localizados em regiões distantes e distintas ${ }^{3}$ do estado de Santa Catarina, possibilitando o estudo comparativo dos resultados.

Inicialmente, ao analisar o estado da arte sobre a produção do

\footnotetext{
3 O estado de Santa Catarina é dividido em oito principais regiões, apresentando grande diversidade tanto geográfica, quanto econômica e cultural. O campus Abelardo Luz, está localizado na região Oeste, enquanto o campus Santa Rosa do Sul encontra-se na região Sul.
} 
conhecimento acerca do tema, observamos que não existem muitos trabalhos sobre a formação integral de sujeitos na ME. Em grande parte das produções, é apenas citada como parte do programa de assistência estudantil, não recebendo a devida atenção. Sendo assim, justificou-se a necessidade de refletir sobre as contribuições da ME para a formação integral dos/as sujeitos/as, por meio dessa pesquisa.

O objetivo geral residiu em investigar os limites e as potencialidades da ME enquanto promotora de formação integral dos/as estudantes do Curso Técnico em Agropecuária Integrado ao Ensino Médio do Instituto Federal Catarinense-IFC. Analisamos as relações estabelecidas na/com a ME e suas contribuições para a formação integral dos/as estudantes que nela residem/residiram. A ME faz parte de um conjunto de políticas públicas de assistência estudantil, mas não se reduz a esse papel, constituindo-se também como um ambiente de construção da cidadania, da dignidade e autonomia desses/as jovens.

Como objetivos específicos, após levantar o estado da arte da produção do conhecimento teórico/empírico acerca da ME, buscamos refletir sobre o Ensino Médio Integrado (doravante EMI) na perspectiva da formação integral dos/as sujeitos/as, além de compreender as possíveis mediações da escola e do trabalho na (re)construção das identidades juvenis e averiguar as percepções de estudantes e egressos/as sobre o papel da ME enquanto espaço de formação integral dos/as sujeitos/as. Por fim, desenvolvemos um produto educacional do tipo Carta Aberta, destinado aos/às gestores/as do IFC, com a finalidade de apresentar os resultados da pesquisa e reivindicar a valorização da $\mathrm{ME}$ como espaço de formação dos/as sujeitos/as.

Inicialmente chamado de ensino secundário, o Ensino Médio (doravante $E M)$ teve sua origem no Brasil entre os séculos XVI e XVIII, sendo restrito à classe dominante e apresentando forte influência religiosa. Sendo assim, acabou contribuindo para a reprodução social (QUEIROZ et al., 2009), servindo aos interesses da elite e consolidando a divisão social do trabalho. Apenas com a chegada da família Real ao Brasil, algumas iniciativas quanto à formação básica de crianças e jovens pobres, órfãos/ãs ou abandonados/as foram criadas, como foi o Colégio das Fábricas (1809) e dos Asilos da Infância dos Desvalidos (1874). É importante destacar que as instituições destinadas à formação da classe trabalhadora apresentavam forte caráter 
assistencialista, formando para a conformação social (BRASIL, 2007).

Em 1909, o acesso à Educação Profissional e Tecnológica foi ampliado com a criação de 19 escolas de Aprendizes e Artífices, pelo presidente Nilo Peçanha. A oferta de educação à classe trabalhadora tinha como finalidade a formação instrumental, voltada para a preparação para o mercado de trabalho, enquanto a elite poderia, por meio de sua formação propedêutica, acessar o ensino superior.

Muitas reformas aconteceram ao longo dos anos, inclusive com a criação da Lei de Diretrizes e Bases da Educação (LDB) № 4024/1961, que ampliou a atuação da iniciativa privada na educação. Enquanto a classe trabalhadora recebia uma formação geral reduzida, sendo privilegiados os conteúdos práticos voltados à formação profissional, a classe dominante estudava para ingressar no Ensino Superior (BRASIL, 2007).

Em 1971, durante a Ditadura Militar, uma nova LDB (no 5692/1971) foi criada, determinando a formação profissional compulsória no EM (QUEIROZ et al., 2009). A medida tinha como objetivo atender ao processo de industrialização. No entanto, suas consequências são observadas ainda hoje, visto que as instituições privadas não modificaram profundamente seus currículos, mantendo a dominância dos conteúdos propedêuticos e intensificando a dualidade educacional entre classe trabalhadora e classe dominante (BRASIL, 2007).

Após o fim da Ditadura Militar, com a criação da Constituição Federal (1988), discussões sobre uma reforma educacional originaram a LDB № 9.394/96. O texto da Lei não foi claro quanto à organização da Educação Profissional, permitindo interpretações que justificaram a criação do Decreto no $2.208 / 97$. Sua implicação foi a separação total entre educação básica e educação profissional, ou seja, foi proibida a oferta de cursos técnicos integrados ao ensino médio. Sendo assim, as instituições deveriam ofertar cursos exclusivamente profissionalizantes ou exclusivamente propedêuticos, acentuando a dualidade já existente.

Apenas em 2004, com o Decreto ํo 5.154/04, o referido decreto foi revogado e o EMI volta a ter espaço, a partir de discussões acerca da proposta de formação politécnica como uma alternativa para a superação do sistema dual de educação, propondo a formação integral dos/as sujeitos/as. O EMI, ao oferecer uma formação ampla, incluindo todas as dimensões da vida humana e compreendendo o 
trabalho como princípio educativo, possibilitará a inserção desses/as sujeitos/as de forma digna na sociedade e no mundo do trabalho (BRASIL, 2007).

A criação do Instituto Federal Catarinense deu-se nesse contexto, como uma política de expansão da Educação Profissional e Tecnológica, que em 2008, através da Lei oㅜ 11.892/08, criou os Institutos Federais de Educação, Ciência e Tecnologia. As instituições são consideradas referência na oferta de Educação Profissional e Tecnológica e, através de ações de ensino em diferentes níveis, da pesquisa e da extensão, objetiva alcançar a formação humana integral e potencializar o desenvolvimento socioeconômico local, regional e nacional (BRASIL, 2007).

O IFC conta atualmente com 15 unidades, nas cidades de Abelardo Luz, Araquari, Blumenau, Brusque, Camboriú, Concórdia, Fraiburgo, Ibirama, Luzerna, Rio do Sul (uma unidade urbana e uma unidade rural), Santa Rosa do Sul, São Bento do Sul, São Francisco do Sul, Sombrio e Videira, além da Reitoria, localizada em Blumenau (IFC/CECOM). Seu principal documento norteador é o Plano de Desenvolvimento Institucional (PDI, 2019), no qual são apresentadas sua missão "proporcionar educação profissional, atuando em Ensino, Pesquisa e Extensão, comprometida com a formação cidadã, a inclusão social, a inovação e o desenvolvimento regional e sua visão de "ser referência nacional em educação profissional, científica e tecnológica, para o mundo do trabalho, por meio da formação cidadã." (p. 34).

Além da estrutura presente normalmente em escolas de EM e instituições de formação profissional, os campi Abelardo Luz, Camboriú, Concórdia, Rio do Sul e Santa Rosa do Sul possuem ME disponíveis para estudantes, principalmente devido aos cursos que se realizam em turno integral e, também, para atender aos/às estudantes de outras regiões que necessitam desse suporte (PDI, 2019). Sendo assim, a pesquisa foi realizada no campus Avançado Abelardo Luz, criado no ano de 2015, fruto das articulações entre o IFC e os movimentos sociais do campo na região e no campus Santa Rosa do Sul, criado em 1993 como uma extensão da Escola Técnica Federal de Santa Catarina (IFC/CECOM).

Consideramos essencial também conhecer as bases conceituais que fundamentam a Educação Profissional e Tecnológica (EPT) no Instituto Federal Catarinense (IFC). Para compreender os princípios que norteiam a EPT do IFC é 
importante refletir sobre o papel da educação, do trabalho, da ciência, da tecnologia e da cultura na vida humana e como essas dimensões se articulam.

Primeiramente, trataremos do trabalho, que segundo a filosofia marxiana/marxista é inerente ao ser humano, que produz, por meio do referido, à própria existência e que precisa compreender os fenômenos naturais e sociais envolvidos nos processos produtivos. É a partir dessa necessidade que surge a demanda pelo domínio de determinados conhecimentos e práticas. A assimilação desses se dá através das relações entre ser humano e natureza e de seres humanos entre si, e a escola se configura como um ambiente formal no qual tais relações se estabelecem, numa perspectiva dialética, pois pode auxiliar a questionar o status quo, visando modificá-lo; ou então, pode auxiliar para a manutenção do mesmo (MOURA, LIMA FILHO e SILVA, 2015).

A problemática com relação à escola é que desde a sua origem esteve destinada às elites e ainda hoje, embora seja considerada um local de instrução formal universal, reproduz a exclusão da classe trabalhadora por meio da diferença de qualidade, já que à classe dirigente está destinada a educação com o intuito de continuar a decidir acerca dos rumos da sociedade, enquanto para a classe trabalhadora, muitas vezes é destinada uma educação meramente instrumental. Entendemos, ainda, que uma educação de qualidade para a classe trabalhadora passa pelo acesso ao conhecimento e à cultura historicamente produzidos, bem como com a rotunda crítica às contradições do modo de produção capitalista, fomentando as condições para a superação do mesmo, ou, dito de outro modo, fomentando a revolução. Apesar de não ser a fonte das desigualdades sociais, a escola muitas vezes é responsável por perpetuá-las (SAVIANI, 2007). No caso do EM e da Educação Básica como um todo, oferecida à classe trabalhadora, sabe-se que contemplam apenas uma dimensão, a do mercado (MOURA, LIMA FILHO e SILVA, 2015).

Ao planejar a formação de nível médio, é importante romper com esse compromisso de servir ao mercado. Ramos (2010) coloca que o EMI como uma possibilidade e justifica ao apresentar seus três sentidos: filosófico, epistemológico e político. O primeiro está relacionado à concepção de formação humana integral/omnilateral, pois possibilita a integração das dimensões fundamentais da vida humana (trabalho, cultura, ciência e tecnologia). O segundo relaciona-se com a 
perspectiva do conhecimento em sua totalidade. Sendo assim, considera a potencialidade do EMI na superação da fragmentação das ciências, entendendo a realidade como um todo, criado através das articulações entre fenômenos naturais e sociais diversos. Por último, temos o sentido político, relacionado à realidade brasileira frente ao capital. Observa-se que os/as jovens da classe trabalhadora não têm a oportunidade de aguardar a formação superior para depois ingressarem no mercado de trabalho.

$\mathrm{O}$ que se pretende não é reduzir o $\mathrm{EMI}$ a um desses sentidos. $\mathrm{O}$ que se espera é que, ao compreender a constituição da dualidade estrutural na sociedade brasileira e da divisão social do trabalho, seja possível lutar pela sua superação. Desse modo, a formação integrada deve ganhar um novo sentido, ao basear-se nos conceitos de educação unitária, omnilateral, politécnica e tecnológica. Sentido esse que busque a relação entre parte e totalidade, que busque a apropriação intelectual do conhecimento científico e tecnológico, que seja indissociável da formação política e ética e assim possibilite formas de intervenção efetiva na sociedade (CIAVATTA, 2014).

É importante salientar que o EMI deve possibilitar mais do que a articulação entre a formação básica e a profissional. O objetivo central deve ser a formação de sujeitos/as críticos/as, autônomos/as e que serão capazes de ler o mundo e buscar a transformação da sociedade. A partir da articulação dos conceitos de trabalho como princípio educativo (dimensão do trabalho), da indissociabilidade entre ensino pesquisa e extensão (dimensão da ciência e da tecnologia), e da formação ética e social (dimensão da cultura), será possível alcançar a formação humana integral pelas vias da edificação das ferramentas para tal, a saber, consciência crítica acerca das contradições do capitalismo, como aludimos, podendo ser condição de uma ação superadora dessa sociedade, portanto, revolucionária .

O IFC apresenta o EMI como uma possibilidade de reconstituir a totalidade dos/as sujeitos/as, através da articulação das dimensões humanas. Essa integração se dará pelo currículo, pelas abordagens contextualizadas e por outras tantas ações que incluem o ensino, a pesquisa e a extensão na instituição e, por que não, da vivência na ME. 
A educação é um processo que se desenvolve em diferentes espaços e tempos, inclusive na escola, mas não apenas nela. Ao analisar o contexto específico das escolas que atuam em tempo integral, como ocorre nos locais em que a pesquisa foi realizada, consideramos que existe uma responsabilidade extra com relação à formação integral dos/as jovens. A ME não deve ser tomada apenas como um "alojamento" ou uma "hospedagem" para os/as estudantes que moram longe da instituição. O seu espaço e o tempo em que os/as sujeitos/as passam na moradia devem estar integrados ao currículo, possibilitando uma formação que ultrapassa a articulação entre formação técnica e formação básica, destinando-se também à formação humana e cidadã e, consequente, à constituição da identidade dos/as sujeitos/as (ESPIT, 2014).

No IFC, a Resolução № 59/2019 dispõe sobre o Regulamento da Moradia Estudantil. Segundo o documento, a ME é destinada a estudantes matriculados/as em cursos presenciais, compondo as ações de permanência e êxito, apresentando como finalidades, a oportunizar o acesso e a permanência, a promoção da inclusão social e o desenvolvimento e aprimoramento do senso de responsabilidade por meio do cuidado com os espaços da instituição. $O$ atendimento prioritário é de estudantes do EMI, menores de 18 anos, em especial aqueles com algum nível de vulnerabilidade social e/ou dificuldades de acesso diário ao campus.

Espit (2014) divide os espaços de convivência dos/as estudantes internos/as em duas categorias. Na primeira estão os espaços privativos: quarto, banheiro, espaços de convivência específicos da ME e os espaços coletivos: refeitório, auditório, biblioteca, laboratórios, áreas de produção. Cada um desses espaços apresenta regras de conduta pré-estabelecidas e a articulação entre eles possibilita uma formação de fato integral. Destaca, no entanto, que as condições físicas, materiais e afetivas são determinantes nesse processo.

Isto é, nas instituições onde os ambientes e as condições são propícias para viver e estudar; onde os projetos, as práticas administrativas, as práticas pedagógicas e as relações pessoais são assentadas em valores universalmente desejados, como diálogo, respeito, justiça, dignidade, solidariedade, entre outros, a possibilidade de uma "boa" formação pessoal e profissional aumenta significativamente. (p. 139) 
Marcelino (2013) apresentou em sua dissertação de mestrado uma discussão justamente sobre o tempo livre no espaço da ME, chamada pela autora de internato. Destaca, em seu trabalho, que o ócio é um direito humano, apesar de não se estender a toda a população. Os/as jovens, no contexto da ME, ao disporem de tempo livre, podem e devem investi-lo em atividades de lazer, dividido em lazer ativo e lazer passivo.

A grande diferença entre lazer ativo e lazer passivo, apesar de ambos proporcionarem satisfação, é que o lazer ativo enumera uma série de gratificações para os indivíduos, desde relacionamentos até saúde física; mas em atividades de lazer passivo não há gasto de energia e sua única fonte de prazer é o relaxamento. (MARCELINO, 2013, p. 22)

Enquanto uma de nós atuou como plantonista na ME, em Abelardo Luz, observamos o grande investimento do tempo livre no uso do celular, para jogos, vídeos e outras formas de entretenimento. Embora consideremos importantes esses momentos de relaxamento e, até de isolamento, acreditamos na importância de planejar e acompanhar as atividades desenvolvidos no tempo livre dos/as jovens, para oportunizar novos momentos formativos. Por exemplo, atividades esportivas, dança, atividades artísticas, cinema, grupos de debates, clube do livro, ou momentos de formação sobre temas atuais, como uma estudante citou na produção de dados, o bullying.

Por esse motivo, consideramos essencial investigar as concepções dos/as estudantes e egressos/as do Curso Técnico em Agropecuária Integrado ao EM que viveram na ME, para buscar mais elementos sobre suas potencialidades e limitações enquanto espaço de formação humana, profissional, cultural, afetiva, enfim, integral/omnilateral.

\section{Método}

Os dados foram produzidos a partir de uma abordagem qualitativa com a triangulação entre o método da história oral, tendo, para tanto, como base teórica, (MEIHY, 1998). O autor apresenta os três elementos essenciais dessa metodologia: o/a entrevistador/a ou pesquisador/a, o/a entrevistado/a ou sujeito/a de pesquisa e o equipamento de gravação. O caminho da metodologia envolve primeiramente a gravação, que é a produção dos dados em si, na sequência a construção do 
documento escrito, na forma de narrativas, por meio da transcrição. Nessa etapa, é essencial realizar revisões e uma análise prévia e, por fim, é realizada a análise do conteúdo e do discurso propriamente dita. Essa última etapa será realizada em articulação com as/os hipóteses/pressupostos da pesquisa e seus referenciais teóricos. Outros pontos que precisam ser considerados, em se tratando de uma metodologia de pesquisa qualitativa, são o contexto social, histórico e político. Embora envolva o planejamento inicial de um roteiro de entrevista, este não é estanque, podendo ser modificado durante o processo (MEIHY, 1998).

Optamos, na pesquisa, pela história oral de vida, que por meio de questões gerativas de narrativa, como por exemplo "relate sua rotina na moradia estudantil durante a semana", possibilitou a compreensão das atividades que são/eram realizadas pelos/as estudantes na ME e como influenciaram na formação integral dos/as sujeitos/as. Além disso, nos utilizamos do questionário semiestruturado, como alternativa para a realização de parte da pesquisa durante a pandemia de COVID-19, sendo aplicado por meio digital, no caso, o whatsapp.

Os/as nove sujeitos/as pesquisados/as foram levados a refletir e a relatar sobre suas experiências durante a vivência na ME, buscando reconhecer as contribuições destas para sua formação integral, levantando aspectos de sua formação humana e profissional, diferenciais com relação aos/às estudantes que vão para suas casas após o período de aulas e sugestões para a melhoria dos processos educativos, dentro e fora da moradia estudantil, além de questões de conforto e bemestar, como será apresentado nos resultados a seguir.

\section{Resultados}

As questões, tanto no roteiro de entrevista, quanto no questionário aplicado online, foram divididas em categorias, com o objetivo de tipificar as respostas, facilitando a compreensão.

Primeiramente, com o objetivo de compreender os processos de separação familiar e da mudança de rotina, envolvendo novas experiências vividas a partir do ingresso na instituição e na ME, observamos que os/as jovens foram influenciados/as, em sua maioria, por amigos/as e familiares para a escolha do curso e da instituição. Outras motivações, como a possibilidade de cursar o ensino médio junto ao técnico e 
a oferta do ensino público, gratuito e de qualidade também foram citados. Embora tenham demonstrado satisfação com o ingresso na instituição, os/as sujeitos/as demonstraram algumas dificuldades com relação à separação familiar, bem como com relação à adaptação na nova rotina e a convivência com pessoas diferentes. No entanto, relataram que os processos de socialização na ME contribuíram na adaptação, ao evidenciarem a criação de vínculos com os/as colegas de quarto.

A experiência de sair de casa, que muitas vezes só acontece após a conclusão do EM, neste caso é antecipada. Muitas mudanças são somadas, incluindo, passagem do ensino fundamental para o $\mathrm{EM}$, do ensino em um único turno para o turno integral, da educação básica para a sua articulação com a formação profissional, o afastamento dos/as amigos/as, a necessidade de se cuidar sozinho/a, a nova rotina, entre outras. Embora uma das principais fontes de insegurança seja a separação da família é importante destacar o papel desse processo na formação dos/as sujeitos/as. Considerando que um dos objetivos do EM, segundo a LDB, Lei no 9394/96, é o desenvolvimento da autonomia e, recorrendo a Nosella (2011), que trata sobre o princípio pedagógico deste nível de ensino, como a retomada do

[...] tema da indefinição natural e heurística dos adolescentes que estão em busca de autonomia, identidade pessoal e inserção social. Ajudá-los a descobrir, aos poucos, por meio de repetidos ensaios, sua identidade profunda é tarefa da formação escolar média, oferecendo uma formação omnilateral. (NOSELLA, 2011, p. 1061)

Blanc (2009) destaca o papel das diferentes situações às quais o/a jovem é submetido na (re)construção das juventudes e dos elementos que constituem sua identidade pessoal e social. Coloca também que a mudança para a moradia estudantil é uma dessas situações, pois a necessidade de tomar uma atitude mais autônoma, assumir determinadas responsabilidades e cuidar de si possibilita não apenas uma mudança/reconfiguração/ressignificação de identidade, mas uma ressignificação da sua juventude. Sendo assim, embora se trate da formação em um curso técnico, que muitas vezes é reduzido à preparação para o mercado de trabalho, outras dimensões da formação humana podem (e devem) ser alcançadas (SANTOS, 2012).

Quando levados/as a refletir sobre suas expectativas e a realidade encontrada na instituição e na ME, destacaram fortemente a questão da prática, que, segundo eles/as, não ocorre em proporção suficiente. Por este motivo, sugerem a 
realização de atividades práticas no período pós aula. Embora compreendamos a relevância da prática para a formação integral dos/as sujeitos/as, destacamos que é essencial não perder de vista sua relação com a teoria. É importante refletir sobre a supervalorização da prática, que encontra subsídio nos discursos hegemônicos, que se apropriam de uma "pseudoconcreticidade", conceito trabalhado por Kosik (2002). O autor apresenta em sua obra a visão do senso comum sobre a forma como o ser humano interage com a natureza, que se reduz a sua capacidade de observar um fenômeno e assim conhecê-lo ao ponto de poder agir sobre ele. Ao apropriar-se do materialismo histórico-dialético de Marx, apresenta a realidade como um conjunto essência-representação, ou seja, problematiza, não o ato de criar representações da realidade, mas sim sua dissociação do conceito.

Neste sentido, podemos refletir sobre práxis utilitária e práxis transformadora. O que é "vendido" pela mídia e fetichizado pela população e o que é, de fato, práxis - aqui entendida como um constante exercício de reflexão-ação. Sendo assim, na perspectiva de uma formação integral para os/as sujeitos/as, compreendemos que para além de incluir teoria e prática no currículo, a escola, os/as professores e os/as estudantes, precisam entendê-las enquanto unidade. Sendo assim, só seria proveitoso a realização das práticas quando mantida sua unidade com a teoria.

A rotina na ME, segundo os/as jovens, é bastante livre. Apesar de envolver horários para acordar, comer e dormir, além da obrigatoriedade do cuidado e da manutenção dos espaços físicos, não existe o planejamento e o acompanhamento de atividades extracurriculares. Como citado anteriormente, Marcelino (2013) apresenta o tempo livre como essencial e considera o lazer ativo, como um momento que também contribui para a formação dos/as sujeitos/as. No entanto, a ausência de atividades sendo planejadas e desenvolvidas com o propósito de, articuladas com o currículo, garantir a formação integral dos/as sujeitos, é uma limitação do potencial formativa da ME, considerando que os/as sujeitos/as vivem apenas o lazer passivo.

De todo modo, os/as entrevistados/as atribuíram aspectos de sua identidade à experiência na $\mathrm{ME}$, que consideram como diferenciais com relação aos/às estudantes que vão para suas casas após as aulas. Dentre esses, citamos: responsabilidade, foco, organização, paciência, tolerância, amadurecimento, 
valorização do trabalho manual, entre outros. Sendo assim, consideramos o pressuposto da pesquisa confirmado. Embora reconheçamos as limitações, acreditamos ser possível a organização, a nível institucional, com a proposição de ações que levem a ressignificação da ME.

\section{Considerações Finais}

A realização dessa pesquisa partiu da hipótese de que a ME é um espaço privilegiado e com muita potencialidade para, em conjunto com as atividades curriculares, garantir uma formação na perspectiva integral/omnilateral e do questionamento "Em que medida a Moradia Estudantil contribui no projeto de Educação Integral dos/as jovens estudantes do Curso Técnico em Agropecuária Integrado ao EM do IFC nos campi Abelardo Luz e Santa Rosa do Sul?".

Sendo assim, com base nos dados apresentados, podemos concluir que a ME é sim um espaço privilegiado para a formação integral dos/as sujeitos, apresentando como potencialidades a possibilidade de interação com pessoas diferentes, colaborando no senso de empatia, respeito e tolerância. Além disso, o afastamento da família, embora doloroso, contribui para o desenvolvimento da autonomia e para a ampliação do senso de responsabilidade. Viver na ME durante a formação no Curso Técnico em Agropecuária Integrado ao Ensino Médio no IFC oferece os diferenciais do foco, do comprometimento e da organização.

No entanto, o espaço/tempo da ME pode proporcionar mais. Por meio de reflexões e construção de ações institucionais, o tempo livre na ME poderá ser mais bem aproveitado para finalidades formativas, seja por meio de atividades esportivas, culturais ou até mesmo práticas, desde que não seja perdida sua relação de reciprocidade com a teoria. Em suma, a ME pode ser ressignificada e tomada não apenas como parte da Política de Assistência Estudantil, mas como espaço destinado à formação na proposta da integralidade, como deseja o IFC.

\section{Referências Bibliográficas}

BLANC, M. V. O desafio de vir a ser: jovens universitários, moradias. Coletivas e identidades. XXVII Congreso de la Asociación Latinoamericana de Sociología. VIII Jornadas de Sociología de la Universidad de Buenos Aires. Asociación Latinoamericana de Sociología, Buenos Aires. Disponível em < http://cdsa.aacademica.org/000-062/1762> Acesso em: 12 de julho de 2020. 
BRASIL, Ministério da Educação. Lei № 9.394 de 20 de dezembro de 1996 - Lei de Diretrizes e Bases da Educação. Brasília, DF, 1996.

BRASIL, Ministério da Educação. Secretaria de Educação Profissional e Tecnologia. Educação Profissional Técnica de Nível Médio Integrado ao Ensino Médio: Documento Base. Brasília, DF, 2007.

CIAVATTA, M. O Ensino Integrado, a Politecnia e a Educação Omnilateral. Por Que Lutamos? Trabalho \& Educação, Belo Horizonte, MG, v. 23, n. 1, p. 187-205, 2014.

ESPIT, A. C. O Internato no Instituto Federal de Educação, Ciência e Tecnologia: Pensionato ou Educandário? Tese de Doutorado em Educação nas Ciências, UNIJUÍ, ljuí, RS, 2014.

IFC, CECOM. Institucional. Disponível em <ifc.edu.br> Acesso em 03 de maio de 2019.

IFC. Plano de Desenvolvimento Institucional do Instituto Federal Catarinense. Editora IFC, Blumenau, SC, 2019. Disponível em <http://consuper.ifc.edu.br/wpcontent/uploads/sites/14/2019/01/PDI_2019-2023_VERSO_FINAL_07.06.2019__ps_Consuper.pdf> Acesso em: 04/07/2020.

IFC. Regulamento da Moradia Estudantil. 2019. Disponível em $<$ http://estudante.ifc.edu.br/wpcontent/uploads/sites/31/2019/12/Resolu\%C3\%A7\%C3\%A3o-n\%C2\%BA-59.2019CONSUPER-com-anexos.pdf> Acesso em: 04/07/2020.

KOSIK, K. Dialética do Concreto. Rio de Janeiro: Paz e Terra, 2002.

MARCELINO, D. de S. C. Tempo Livre no Internato: E agora, o que fazer? Dissertação de Mestrado em Educação Agrícola, UFRRJ, Seropédica, RJ, 2013.

MEIHY, J. C. S. B. Manual de história oral. $2^{\underline{a}}$ ed. São Paulo: Loyola, 1998.

MOURA, D. H.; LIMA FILHO, D. L.; SILVA, M. R. Politecnia e Formação Integrada: Confrontos Conceituais, Projetos Políticos e Contradições Históricas da Educação Brasileira. Revista Brasileira de Educação, Rio de Janeiro, RJ, v. 20, n. 63, p. 10571080, 2015.

NOSELLA, P. Ensino Médio: Em Busca do Princípio Pedagógico. Educação \& Sociedade, Campinas, SP, v. 32, n. 117, p. 1051-1066, 2011.

QUEIROZ, C. M.; ALVES, L. A.; SILVA, R. R. da.; SILVA, K. N. da.; MODESTO, R. V. Evolução do Ensino Médio no Brasil. IN: V simpósio internacional: O estado e as políticas educacionais no tempo presente - UFU, Uberlândia, 2009. Disponível em <http://www.simposioes-tadopoliticas.ufu.br/imagens/anais/pdf/EP07.pdf>. Acesso em 20 de maio de 2019 
RAMOS, M. Ensino Médio Integrado: Ciência, Trabalho e Cultura na relação entre Educação Profissional e Educação Básica. IN.: MOLL, J. Educação Profissional e Tecnológica no Brasil Contemporâneo: Desafios, Tensões e Possibilidades. Porto Alegre: Editora Artimed, 2010.

\section{SANTOS, M. G. C. A Categoria de Formação Omnilateral em Marx e o Trabalho}

Enquanto Princípio Educativo. In: I Seminário Internacional e I Fórum de Educação do Campo da Região Sul do RS: Campo e Cidade em busca de Caminhos Comuns. Pelotas, RS, 2012. Disponível em < http://coral.ufsm.br/sifedocregional/images/Anais/Eixo\%2005/Magda\%20Gisela\%20 Cruz\%20dos\%20Santos.pdf> Acesso em 07 de julho de 2020.

SAVIANI, D. Trabalho e Educação: Fundamentos Ontológicos e Históricos. Revista Brasileira de Educação, Rio de Janeiro, RJ, v. 12, n. 34, p. 152-180, 2007.

\section{Eliane Juraski Camillo}

Florianópolis, Santa Catarina, Brasil

Doutora em Educação e docente do Instituto Federal Santa Catarina (IFSC), atuando no

Centro de Referência em Formação e EaD - Cerfead.

E-mail: juraskicamillo@gmail.com

Lattes: http://lattes.cnpq.br/9912314419153233

\section{Daiana Colombro Figueredo}

Florianópolis, Santa Catarina, Brasil

Mestra pelo Programa de Mestrado PROFEPT, doutoranda em Educação Científica e Tecnológica, no PPGECT UFSC e docente do Instituto Federal Catarinense (IFC).

E-mail: daiqmclic@gmail.com

Lattes: http://lattes.cnpq.br/8463347995002390

\section{Q.Code}

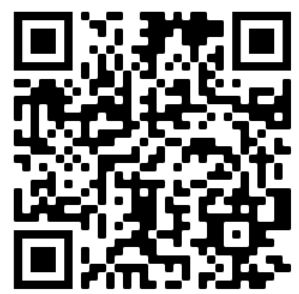

\section{Editores-Responsáveis}

Dr. Enéas de Araújo Arrais Neto, Universidade Federal do Ceará, UFC, Ceará, Brasil

Dr. Sebastien Pesce, Universidade de Orléans, França 